\title{
Morfologia renal do Bradypus torquatus
}

\author{
Pedro Kastein Faria da Cunha Bianchi ${ }^{1}$ \\ Fernanda Cardoso ${ }^{1}$ \\ Maria Letícia Baptista Salvadori ${ }^{1}$ \\ Ana Rita de Lima ${ }^{2}$ \\ Graziela Menck Ferreira Santos ${ }^{1}$ \\ José Roberto Kfoury Junior ${ }^{1}$ \\ ${ }^{1}$ Faculdade de Medicina Veterinária e Zootecnia, Universidade de São Paulo \\ Departamento de Cirurgia, Setor Anatomia dos Animais Domésticos e Silvestres \\ Avenida Prof. Dr. Orlando Marques de Paiva, 87, CEP 05508-270, São Paulo - SP, Brasil \\ ${ }^{2}$ Faculdade de Medicina Veterinária, Universidade Federal Rural da Amazônia \\ Instituto de Saúde e Produção Animal \\ Avenida Presidente Tancredo Neves, 2501, CEP 66077-530, Belém - PA, Brasil \\ * Autor para correspondência \\ pedro.bianchi@usp.br
}

\section{Resumo}

Dentre os Xenarthras, as preguiças apresentam uma ingestão hídrica restrita à água das folhas, frutas e legumes. Como primeira abordagem para verificar se esses animais possuem alguma diferença morfofisiológica que possa justificar ou compensar essa baixa ingestão hídrica, investigou-se a anatomia renal desses animais, particularmente a da preguiça-de-coleira (Bradypus torquatus). Os rins desses animais foram analisados macroscopicamente, pela microscopia de luz e pela microscopia eletrônica de varredura. Os rins do Bradypus torquatus são órgãos pares em forma de grão de feijão, localizados dorso-cranialmente à cintura pélvica, entre o peritônio e a parede posterior do abdome. A utilização das técnicas histológicas possibilitou identificar, na região cortical, os corpúsculos e túbulos renais e, na região medular, uma quantidade significativa de tecido intersticial com um ducto coletor. Os resultados deste estudo mostraram que apesar do Bradypus torquatus não ingerir água diretamente, seu rim não difere da maioria dos mamíferos, apresentando as mesmas estruturas anatômicas, sugerindo que esses animais alcançam plenamente suas necessidades hídricas pelo consumo de folhas, frutas e brotos. Contudo, a fim de confirmar essa hipótese, estudos sobre a eficiência da reabsorção hídrica, como o sistema renina-angiotensina-aldosterona, necessitam ser realizados.

Palavras-chave: Bradypus torquatus; Morfologia renal; Preguiça-de-coleira

\section{Abstract}

Renal morphology of Bradypus torquatus. Among the Xenarthras, sloths present a hydric ingestion restricted to water from leaves, fruits, and vegetables. As a first approach to verify whether these animals have some morphophysiological difference which could justify or compensate this low hydric ingestion, the renal anatomy of these animals was investigated, particularly that of maned sloth (Bradypus torquatus). Kidneys from 
these animals were macroscopically analyzed, through light microscopy and scanning electron microscopy. The Bradypus torquatus kidneys are bean-shaped paired organs, located dorso-cranially to the pelvic girdle, between the peritoneum and the posterior abdominal wall. The use of histological techniques allowed us to identify, in the cortical region, the renal corpuscles and tubules, and, in the medullary region, a significant amount of interstitial tissue with a collecting duct. The results of this study showed that, although Bradypus torquatus doesn't drink water directly, its kidneys doesn't differ from that of most mammals, presenting the same anatomical structure, suggesting that these animals fully reach their hydric needs, basically by consuming leaves, fruits, and sprouts. Nevertheless, in order to confirm this hypothesis, studies on the effectiveness of water reabsorption, such as the renin-angiotensin-aldosterone system, must be carried out.

Key words: Bradypus torquatus; Maned sloth; Renal morphology

\section{Introdução}

Atualmente existe uma enorme preocupação com a preservação da natureza e dos animais que dependem dela para sua sobrevivência. Com o avanço das fronteiras agrícolas, o meio ambiente está sendo fortemente alterado proporcionando significativas mudanças à fauna e a flora, ameaçando o habitat natural de algumas espécies. Visando a preservação dos animais silvestres, particularizando a ordem dos Xenarthras, torna-se de fundamental importância o desenvolvimento de pesquisas buscando o entendimento anatômico dos órgãos das espécies pertencentes a esta ordem, como o Bradypus torquatus ou preguiça de coleira, realizando uma correlação com o seu modo de vida e seu habitat.

Segundo Barreto (2009), o Choloepus, pertencente ao grupo das preguiças, geralmente obtém as suas necessidades de água das folhas (umbaúba, ingazeira, figueira), frutas e legumes que ingere seletivamente em sua dieta, por isso, quando em vida livre, as preguiças de um modo geral não tem o hábito de beber água em poças, lagoas ou rios (BRITTON, 1941). Devido a esse fator, a fim que esses animais consigam suprir sua dieta hídrica para a mantença da sua sobrevivência, torna-se necessário que habitem uma área florestal relativamente grande (SANTOS, 1945; CUBAS et al., 2007). Ainda, foi observado, em cativeiro, que as preguiças podem ingerir água através da lambedura de folhas molhadas (GILMORE et al., 2000).

Neste contexto, infere-se a hipótese de que as preguiças tenham uma ingestão hídrica pobre, e que deva existir um sistema que permita a economia de água no organismo dos mesmos. Dessa forma, torna-se importante averiguar a anatomia renal desses animais, verificando se existe alguma diferença morfofisiológica que possa justificar esta baixa ingestão hídrica.

O rim nos mamíferos pode assumir formatos anatômicos variáveis, porém a sua função não sofre nenhuma alteração. Nos bovinos o rim apresenta um formato multilobado, já nos carnívoros e no Bradypus torquatus possui uma arquitetura que lembra um grão de feijão (JUNQUEIRA; CARNEIRO, 2010; KONIG; LIEBICH, 2011). Ambos os órgãos estão localizados na cavidade abdominal, fixados a parede do abdome, recobertos pelo peritônio, lembrando que o rim direito assume uma posição mais cranial em relação ao rim esquerdo. Possuem a região cortical decomposta em zonas triangulares pelos raios medulares que provém da camada medular do órgão. A camada cortical destaca-se pela presença de túbulos secretores e pela existência de corpúsculos renais, sendo uma estrutura de fácil reconhecimento devido a sua forma esferoidal e a presença de numerosos núcleos (DYCE et al., 2010).

A região medular é constituída de tubos separados entre si por uma camada considerável de tecido conjuntivo. Ainda, envolvendo o órgão existe uma cápsula fibrosa e, mais externamente, um tecido conjuntivo rico em células adiposas, chamado de tecido adiposo Peri-renal (BANKS, 1992). Tais órgãos não são lobados e não apresentam papila urinária, ocupando a cavidade abdominal na posição usual nos Dasypodidae, porém nos Myrmecophagidae e nos Bradypodidae o órgão desceu para a cavidade pélvica, mantendo os pontos habituais de inserção da artéria aorta e da veia cava inferior (BARRETO, 2009). 
No rim, existe o aparelho justaglomerular, muito importante devido a produção e armazenamento da renina. Esta é uma proteína liberada pelo órgão quando a pressão arterial atinge baixos níveis. Quando e renina é liberada ocorre a transformação da angiotensina I em agiotensina II que é um potente vasoconstritor, podendo causar uma vasoconstrição arterial, aumentando a reabsorção de líquidos e, consequentemente, elevando a pressão arterial (GUYTON; HALL, 2006).

A proposta deste trabalho é analisar, através da microscopia eletrônica de luz e de varredura, o rim da preguiça de coleira (Bradypus torquatus), identificando suas estruturas para conhecer suas particularidades, buscando compreender melhor a fisiologia e anatomia do órgão desta espécie, verificando se existe alguma diferença morfofisiológica que justifique e talvez compense a sua baixa ingestão hídrica.

\section{Material e Métodos}

Para o desenvolvimento da pesquisa foram utilizados dois rins do Bradypus torquatus. O material foi cedido para a Faculdade de Medicina Veterinária e Zootecnia (FMVZ - USP), Departamento de Anatomia dos Animais Domésticos e Silvestres, pela Reserva Zoobotânica - Matinha Ilhéus/Bahia (Registro Ibama $\mathrm{n}^{\mathrm{o}}$ 02006.001.348/98-31).

Após a obtenção do material, foi realizado o processamento do mesmo pelas técnicas usuais de microscopia de luz. O rim foi desidratado por vários etanóis com concentrações de $70 \%$ até $100 \%$. Em seguida, o órgão foi diafanizado em uma solução de xilol e submetido à inclusão em similar de parafina.

Cortes de $5 \mu \mathrm{m}$ de espessura foram feitos com o auxilio de um micrótomo automático (OLYMPUS DP71) e os mesmos foram fixados em laminas e incubados em estufas a $60^{\circ} \mathrm{C}$ para desparafinização.

Em seguida, os cortes foram corados pelas técnicas de hematoxilina e eosina (HE) e tricromo de Masson para verificação de colágeno. Após a coloração, os cortes foram observados em microscópio de luz (Nikon Eclipse E-800).
Para a análise microscópica eletrônica de varredura, parte dos fragmentos $\left(2 \mathrm{a} 3 \mathrm{~mm}^{3}\right)$ foi submetida à fixação por glutaraldeído à $2,5 \%$, em tampão fosfato $0,1 \mathrm{M},(\mathrm{pH}$ 7,4). A fixação foi realizada em temperatura ambiente por $2 \mathrm{~h}$ e a solução fixadora foi removida com três lavagens de 15 min com tampão fosfato $0,1 \mathrm{M}$. O restante dos fragmentos foram submetidos a uma temperatura de $-20^{\circ} \mathrm{C}$ por $24 \mathrm{~h}$.

Logo em seguida, o material foi criofraturado e pós fixado com tetróxido de ósmio $\left(\mathrm{O}_{\mathrm{s}} \mathrm{O}^{4}\right)$ 1\% em tampão fosfato $0,1 \mathrm{M}(\mathrm{pH} 7,4)$ por uma hora. Posteriormente às lavagens com o tampão fosfato $0,1 \mathrm{M}(\mathrm{pH} 7,4)$ e água destilada, para a remoção do excesso de fixador, as amostras receberam tratamento com ácido tânico $1 \%$, por uma hora.

Realizou-se a desidratação em série gradual de etanol, submetendo o material à secagem por ponto crítico usando $\mathrm{CO}_{2}$ Em seguida, o material foi montado em um suporte (Stub), utilizando cola de carbono, recebendo um recobrimento metálico com ouro por "Sputtering". As observações foram feitas em um MEV (LEO $435 \mathrm{VP}$ ) de $15 \mathrm{kV}$.

\section{Resultados}

A observação microscópica evidenciou claramente as regiões cortical e medular do rim, mostrando que os lobos renais são fundidos, formando um único órgão, classificado como unipiramidal (Figura 1A).

$\mathrm{Na}$ região cortical verificou-se a presença de corpúsculos renais (Figura 1C), estes formam o glomérulo (Figura 1D), o folheto visceral e parietal que originam a cápsula glomerular (Figura 1C) e, saindo dos corpúsculos renais seguindo em direção a pelve renal apresentam-se os ductos coletores (Figura 1B).

Envolvendo o órgão observa-se uma cápsula constituída de tecido fibroso (Figura 1A) e a presença de tecido conjuntivo em algumas regiões mais externas. 
FIGURA 1: Rim de Bradypus torquatus. Em A corte transversal (aumento de 4x): 1 (Cápsula Renal); 2 (Região cortical do rim); 3 (Região medular do rim); 4 (Pelve renal). Coloração: Tricromo de Masson. Em B Micrografia eletrônica de varredura por criofratura mostrando: 1 (Pelve renal); 2 (Ducto coletor). Em C corte transversal (aumento de 100X): 1 (Corpúsculo renal); 1.1 (Camada visceral do corpúsculo renal); 1.2 (Camada Parietal do corpúsculo renal); 1.3 (Mácula Densa). Coloração: HematoxilinaEosina. Em D Micrografia eletrônica de varredura por criofratura mostrando: 1 (Corpúsculo renal).
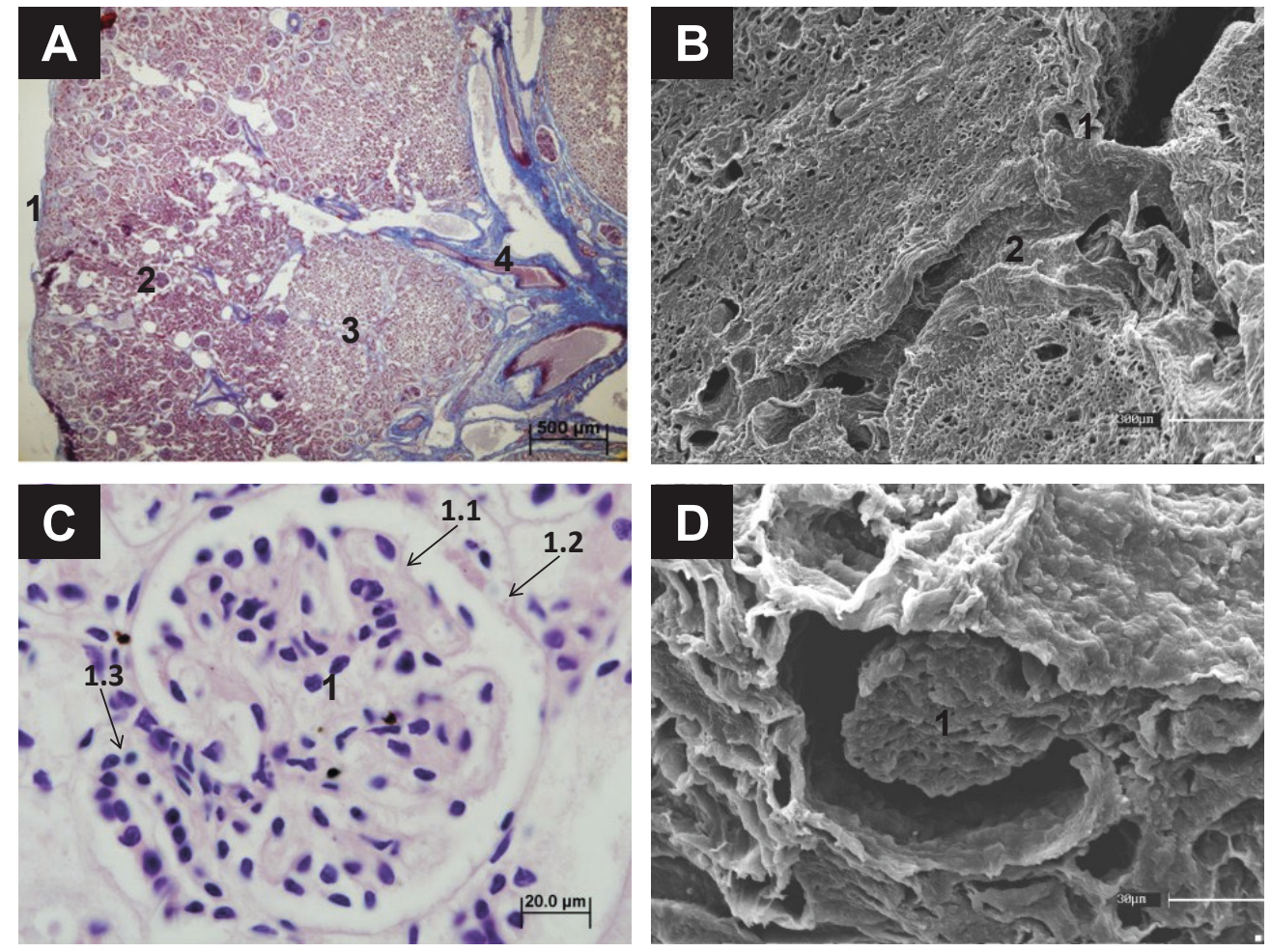

\section{Discussão}

Os rins, no Bradypus torquatus, são órgãos pares em forma de grão de feijão, localizados logo acima da cintura pélvica entre o peritônio e a parede posterior do abdome, não diferindo dos mamíferos que apresentam o órgão com a mesma formação, como os carnívoros. Porém, deve-se ressaltar que, apesar de possuírem um estômago com quatro cavidades com capacidade fermentativa, não apresentam um rim multilobado como o dos bovinos, seguindo o padrão dos pequenos ruminantes, onde o rim é unipiramidal (DYCE et al., 2010).

Envolvendo os rins desta espécie por toda a sua superfície, apresenta-se a cápsula renal, formada por tecido fibroso e, Conforme visto macroscopicamente, o órgão é dividido em basicamente duas regiões, a camada cortical e a camada medular (GETTY, 1986; DYCE et al., 2010). O glomérulo é visto dentro da cápsula glomerular, com a ramificação de uma arteríola em diversas alças

capilares originando a estrutura completa, onde existe duas camadas distintas, a região parietal e visceral (JUNQUEIRA; CARNEIRO, 2010).

Na região do corpúsculo renal, a parede do túbulo que normalmente é constituída por epitélio cubóide, tornando-se cilíndrico com células bastante estreitas, formando uma linha de núcleos justapostos originando a mácula densa, sugerindo a existência o aparelho justaglomerular (BANKS, 1992). Devido a presença do aparelho justaglomerular, pode-se inferir que o mecanismo da renina-angiotensina-aldosterona seja uma solução para aumentar a reabsorção de água. Porém o aparelho justaglomerular também esta presente no rim de outros mamíferos que tem uma ingestão hídrica bastante elevada, como os carnívoros.

Os ductos coletores foram vistos saindo do glomérulo em direção à pelve renal, onde o ducto coletor, que é um segmento subsequente do túbulo contorcido distal, é responsável por conduzir o filtrado até a pelve 
renal, que apresenta-se dilatada, funcionando como um funil para guiar a urina ate o ureter, mostrando que o Bradypus torquatus se enquadra nos padrões de função renal dos mamíferos (GETTY, 1986; KONIG; LIEBICH, 2011).

Esses animais não são habituados a ingerir água quando estão em seu habitat natural. Porém, para que o fato seja plausível de concordância, é necessário que esses animais disponham de uma boa área florestal, para que possam comer em quantidade suficiente satisfazendo as suas necessidades alimentares suprindo seu déficit hídrico, mantendo a sua vida (CUBA, 2007). Caso o animal não consiga manter o seu equilíbrio hídrico somente com a ingestão de folhas, raízes e brotos pode ser que este seja obrigado a ingerir água através da lambedura das folhas, como observado em animais mantidos em cativeiro (SANTOS, 1945; GILMORE et al., 2000).

Os resultados do presente estudo mostraram que o rim do Bradypus torquatus não apresenta diferenças anatômicas que possam causar alterações fisiológicas, porém tais animais não tem o hábito de ingerir água diretamente, sugerindo que estes alcancem suas necessidades hídricas através do consumo de folhas, frutas e brotos, considerando que possuem um metabolismo bastante lento com uma taxa de fermentação bastante baixa, diminuindo, dessa forma, a necessidade hídrica. Também, pode ser que os animais dessa espécie apresentem algum sistema eficiente de reabsorção hídrica como o sistema renina-angiotensinaaldosterona.

Esse trabalho abre novas perspectivas para analisar a ingestão hídrica da preguiça de coleira, visando a compreensão da sua fisiologia. Para a realização desse procedimento pode-se fazer uso da sondagem vesical de forma asséptica, acoplando um sistema de coleta que fique abaixo do animal, ou através da coleta direta de um recipiente colocado abaixo da gaiola do animal. Com a obtenção dos valores de urina excretada pelo animal, seria possível, calcular a ingestão hídrica do mesmo.

\section{Referências}

BANKS, W. J. Histologia veterinária aplicada. 2. ed. São Paulo: Editora Manole, 1992. 655 p.

BARRETO, R. M. F. Uso do habitat pela preguiça de coleira (Bradypus torquatus), no sul da Bahia, Brasil. 2009. $100 \mathrm{f}$. Dissertação (Mestrado em Zoologia) - Universidade de São Paulo, São Paulo. 2009

BRITTON, S. W. Form and function in the sloth. The Quarterly Review of Biology, Chicago, v. 16, p. 190-207, 1941.

CUBAS, S. C.; DIAS, J. C. R.; CATÃO-DIAS, J. L. Tratado de animais selvagens - Medicina Veterinária. São Paulo: Editora Roca, 2007. 1354 p.

DYCE, K. M.; SACK, W. O.; WENSING, C. J. S. Tratado de anatomia veterinária. 4. ed. Rio de Janeiro: Elsevier Editora Ltda, 2010. 834 p.

GETTY, R. Anatomia dos animais domésticos. 5. ed. Rio de Janeiro: Editora Guanabara Koogan, 1986. 2000 p.

GILMORE, D. P.; DA-COSTA, C. P.; DUARTE, D. P. F. An update on the physiology $\mathrm{f}$ two - and three - told sloths. Brazilian Journal of Medical and Biological Research, Ribeirão Preto, v. 33, p. 129146, 2000.

GUYTON, A. C.; HALL, J. E. Tratado de Fisiologia Médica. 11. ed. Rio de Janeiro: Editora Elsevier, 2006. 1115 p.

JUNQUEIRA, L. C.; CARNEIRO, J. Histologia básica. 10. ed. Rio de Janeiro: Editora Guanabara Koogan, 2010. 540 p.

KONIG, E. H.; LIEBICH, H. G. Anatomia dos animais domésticos. 4. ed. Porto Alegre: Artmed, 2011. 787 p.

SANTOS, E. Entre o gambá e o macaco: vida e costumes dos mamíferos no Brasil. 1. ed. Rio de Janeiro: Editora F. Bryiet \& Cia, 1945. $287 \mathrm{p}$. 